\title{
Satisfação de usuários com um programa de Roda de Conversa em sala de espera
}

\author{
Users' satisfaction with a conversation circle program in the \\ waiting room
}

\section{Patrícia Pupin Mandrá1, Fernanda Diniz Faleiros Silveira²}

\begin{abstract}
RESUMO
Objetivo: Investigar a satisfação de participantes com um programa educativo em saúde. Métodos: Participaram voluntariamente da pesquisa 34 adultos, 21 do gênero feminino e 13 do gênero masculino. Para a coleta, foi elaborado um instrumento dirigido com respostas apresentadas em escala Likert (0-5). Os dados obtidos foram categorizados e tabulados para a análise por meio de estatística não paramétrica. Resultados: A temática foi avaliada como muito boa (MB) por $73,8 \%$ dos entrevistados, a estratégia de apresentação como MB por $73,2 \%$, a organização como MB para $70,3 \%$ e a linguagem e o material de apoio como MB para $75,5 \%$ e $57,2 \%$, respectivamente. Sessenta e nove vírgula três por cento dos entrevistados consideraram importante o conteúdo e $44 \%$ estavam preparados para transmitir o conhecimento. Conclusão: Constatou-se que os participantes ficaram satisfeitos com o programa e que as rodas de conversa mostraram-se como uma estratégia efetivamente capaz de produzir a discussão sobre os assuntos colocados em pauta e eficaz para a sensibilização dos participantes frente a sua saúde.
\end{abstract}

Descritores: Promoção em saúde; Educação em saúde pública; Humanização dos serviços; Satisfação do paciente; Fonoaudiologia

\begin{abstract}
Purpose: To investigate the satisfaction of participants with an educational program in health. Methods: Research voluntarily participants were 34 adults, 21 females and 13 males. For the collection was designed an instrument directed with responses presented in Likert scale (0-5). The data were categorized and tabulated for analysis by nonparametric statistics. Results: The program was evaluated as very good (VG) by $73.8 \%$ of those interviewed, the strategy of presentation as VG by $73.2 \%$, the organization was $70.3 \%$ for VG, the language and supporting material for VG were $75.5 \%$ and $57.2 \%$ respectively, and $69.3 \%$ considered it important the content and $44 \%$ were prepared to convey knowledge. Conclusion: It consisted to which participants were satisfied with the program, so the circles of conversation were an effective strategy capable of producing a discussion of the issues placed on the agenda and effective for sensitization of the participants in their health.
\end{abstract}

Keywords: Health Promotion; Health Education; Humanization of Assistance; Patient Satisfaction; Speech, Language and Hearing Sciences

Trabalho realizado no Curso de Fonoaudiologia, Faculdade de Medicina de Ribeirão Preto, Universidade de São Paulo - USP - Ribeirão Preto (SP), Brasil, com bolsa concedida pelo Programa Ensinar com Cultura e Extensão da Universidade de São Paulo (USP).

(1) Departamento de Oftalmologia, Otorrinolaringologia e Cirurgia de Cabeça e Pescoço, Faculdade de Medicina de Ribeirão Preto, Universidade de São Paulo

- USP - Ribeirão Preto (SP), Brasil.

(2) Fonoaudióloga clínica, Ribeirão Preto (SP), Brasil.

Conflito de interesses: Não

Contribuição dos autores: FDFS pesquisador principal, elaboração da pesquisa, elaboração do cronograma, levantamento da literatura, coleta e análise dos dados, redação do artigo; PPM orientadora, elaboração da pesquisa, elaboração do cronograma, análise dos dados, redação e correção do artigo, submissão e trâmites do artigo, aprovação da versão final.

Endereço para correspondência: Patrícia Pupin Mandrá. Av. Bandeirantes, 3900, Monte Alegre, Ribeirão Preto (SP), Brasil, CEP: 14049-900.

E-mail: ppmandra@fmrp.usp.br

Recebido em: 20/2/2013; Aceito em: 12/8/2013 


\section{INTRODUÇÃO}

A universidade é um cenário privilegiado para a divulgação e a propagação do conhecimento científico, interna e externamente. As ações educativas em saúde são estratégias de disseminação de conhecimento à comunidade, bem como de aproximação entre docentes e discentes com a realidade social em que estão inseridos. Para cumprir seu papel social, a universidade vem realizando ações de extensão que articulam e integram os conhecimentos das áreas de Educação e Saúde em benefício da comunidade.

A educação em saúde tem como principal meta a transmissão de informação para mudança de comportamento pessoal em relação à própria saúde ${ }^{(1)} \mathrm{e}$ a capacitação dos indivíduos para agirem conscientemente diante da realidade cotidiana ${ }^{(2)}$. Através de práticas educativas, os profissionais da área da saúde poderiam divulgar o conhecimento científico e atuar sobre a vida cotidiana das pessoas ${ }^{(3)}$.

Uma proposta de educação em saúde deve ser norteada por um modelo educativo. Fundamentado, teoricamente, no modelo de educação em saúde tradicional (preventivo), o profissional alcançaria, em tese, os objetivos da proposta, por meio de informações verticalizadas e da persuasão dos indivíduos ${ }^{(4-6)}$, assumindo o princípio de que a informação adequada deve ser transmitida pelo detentor do conhecimento (o profissional) (3). Em outra vertente teórica, o profissional poderia utilizar o modelo radical/dialógico, que supõe uma efetiva participação da população, combinando escolhas individuais, autonomia, autogestão e responsabilidade social pela saúde, reconhecendo o usuário como portador do saber sobre o processo saúde-doença-cuidado ${ }^{(4,6)}$. Com esse modelo, haveria a responsabilização dos indivíduos pelos seus problemas de saúde e a valorização de estratégias fundamentadas em trocas de experiências para desencadear a reflexão. A base para essa proposta seria a construção conjunta de saberes, por meio de práticas educativas, cuja meta seria promover o aumento da consciência crítica por intermédio da troca de ideias entre os sujeitos, respeitando-se a diversidade das relações humanas ${ }^{(7,8)}$. O modelo dialógico de Educação em Saúde tem sido associado a mudanças duradouras de hábitos e de comportamentos para a saúde, pois a utilização desses princípios possibilitaria a construção de novos sentidos e significados sobre os temas abordados ${ }^{(9)}$.

Com a utilização de recurso comunicativo bidirecional, em lugar do unidirecional, almeja-se o acesso e a democratização do conhecimento científico a todas as camadas sociais, sem perder a precisão técnica.

Uma das estratégias dialógicas de educação em saúde descritas na literatura é a formação de pequenos grupos para a realização de oficinas focais, dinâmicas de grupo, rodas de conversa e jogos coletivos, apoiados em material técnico ilustrativo/ informativo, como folheto, cartaz, vídeo, entre outros ${ }^{(3,6,9-11)}$.

A informalidade da roda de conversa é um exemplo de espaço democrático de aprendizagem, que fomenta a inclusão e a cooperação dos interlocutores e participantes na construção do processo educativo. Nessa estratégia, os conhecimentos dos sujeitos são considerados para o estabelecimento da interlocução e para a análise crítica do conteúdo trabalhado ${ }^{(9)}$. Durante a roda, o profissional (facilitador) se empenhará para desencadear a reflexão e a discussão do tema, a partir da troca e compartilhamento de problemas e soluções, de forma interativa, horizontal e dialógica ${ }^{(11)}$.

Para colocar em prática a roda de conversa, o profissional da saúde deverá, ainda, preocupar-se com sua postura, sua linguagem, com o material de apoio e com o local, pois esses aspectos devem ser adequados ao modelo teórico, ao tema e à comunidade a que se destina, em relação ao gênero, faixa etária, escolaridade, ocupação, nível educativo e socioeconômico. Os temas deverão ser selecionados a partir do interesse dos participantes e da experiência de cada um, com o objetivo de estimular a troca inicial de experiências ${ }^{(10)}$.

O processo comunicacional é uma das questões enfrentadas na humanização em saúde. O sucesso dessas práticas está no desafio que é aprender, reconhecer e negociar com o outro, que detém direitos, autonomia e estoque cultural peculiares ${ }^{(12)}$. O uso de metodologia participativa cria um espaço de discussão e de construção de conhecimento compartilhado entre os indivíduos que participam da atividade ${ }^{(13)}$.

A avaliação da prática educativa desenvolvida é de extrema importância para a revisão crítica do objetivo do programa elaborado, bem como do modelo teórico e estratégias utilizadas. Assim, o usuário do serviço de saúde que participa dessas ações tem papel fundamental como avaliador do programa a ele destinado.

Pesquisadores ${ }^{(6)}$ estudaram a eficácia de um programa desenvolvido com Agentes Comunitários de Saúde, cujo tema foi a Fonoaudiologia. O modelo educativo adotado foi o relato de experiência pessoal. Os dados foram obtidos com a realização de uma entrevista coletiva semiestruturada pré-intervenção e por meio da técnica de Grupo Focal pós-intervenção. Os pesquisadores concluíram que a intervenção educativa realizada com base na concepção do modelo de educação radical demonstrou-se eficiente para a abordagem dos assuntos propostos pelo grupo.

Fonoaudiólogos desenvolveram um trabalho com educadores, através de planejamento e realização de oficinas para a promoção de saúde. Concluíram que as oficinas propiciaram a discussão sobre os temas desenvolvidos e a oportunidade para que os participantes construíssem o saber e o aplicassem em suas práticas diárias, com autonomia ${ }^{(14)}$.

Autores avaliaram a efetividade de um processo educativo realizado por meio de exposição oral, em que os participantes eram estimulados a relatar seus interesses e experiências relacionados ao tema proposto, a partir de um álbum seriado com ilustrações. Ao final do programa, foi distribuído um manual com linguagem simples e com ilustrações que reforçavam todos os tópicos abordados. Para avaliar o conhecimento do 
grupo, foi elaborado um questionário. Os resultados indicaram que o processo educativo mostrou-se eficiente, uma vez que melhorou o conhecimento sobre o tema, constituindo-se em um modelo de atuação efetiva e de baixo custo, que também pode ser aplicado para a promoção de saúde ${ }^{(10)}$.

A experiência com o desenvolvimento de rodas de conversa em dois hospitais, um público e outro particular, já foi descri$\mathrm{ta}^{(11)}$. Foram promovidas três rodas de conversa, interdisciplinares e intersetoriais, compreendendo 40 trabalhadores, entre médicos, psicólogos, enfermeiros, assistentes sociais, auxiliares administrativos, fisioterapeutas, operadores de serviços gerais e outros. A duração total das rodas foi de 150 minutos. Durante as atividades, os facilitadores procuraram refletir e discutir sobre o assunto com os participantes. As rodas de conversa mostraram ser um método promissor e efetivo para provocar mudanças nos ambientes de saúde, pois o trabalho coletivo fortaleceu o pensamento solidário e um novo modo de promover a saúde.

Ação educativa realizada por enfermeiras e assistentes sociais, com a intenção de sensibilizar trabalhadores quanto ao uso do cigarro em ambientes coletivos, foi avaliada. $\mathrm{O}$ trabalho foi desenvolvido por meio das seguintes estratégias: a) teatro de bonecos; b) levantamento sobre conhecimentos e comportamentos com relação ao hábito de fumar; c) jogos educativos de perguntas e respostas sobre o tema abordado; d) rodas de conversa com encontros do grupo para discussão do tema com informalidade; descontração, livre expressão de dúvidas, vivências e testemunho de vida; e) palestras com apresentação de vídeos-debate e distribuição de folders educativos. Após a avaliação do programa, constatou-se o surgimento de mudanças eficazes nos participantes e concluiu-se que a transmissão do conhecimento com as orientações adequadas, realizada por profissionais treinados, é fundamental para a prevenção dos agravos de saúde, estabelecendo, sobretudo, informações de maneira global, incentivando, assim, a consciência dos indivíduos nas mudanças do estilo de vida e de comportamento ${ }^{(15)}$.

Em um projeto realizado por funcionários de serviços de saúde e comunicadores de rádios comunitárias, foram criadas oficinas de trabalho (13 encontros com quatro horas de duração), a fim de se discutir, refletir e criar ações conjuntas sobre temas de saúde. Para abordar os assuntos, foram usados textos acadêmicos, poesias, músicas, criação de uma novela e pinturas. Os responsáveis tiveram a preocupação em evitar que as oficinas fossem desenvolvidas de forma linear e unidirecional, priorizando as experiências e interpretações dos participantes. A avaliação final foi feita por meio de um questionário sobre as oficinas, material utilizado e incorporação de conhecimentos. Após a análise das respostas, concluiu-se que a metodologia foi compatível com o objetivo, uma vez que houve o envolvimento dos participantes e o desenvolvimento de parcerias entre eles, ao longo do projeto ${ }^{(5)}$.

Assumindo-se o pressuposto de que em ações extensionistas deve existir troca entre os saberes da universidade e da comunidade local ${ }^{(16)}$, foi implantado e desenvolvido na sala de espera do Centro Integrado de Reabilitação do Hospital Estadual de Ribeirão Preto (CIRHER), SP, durante o ano de 2011, um programa socioeducativo, com enfoque na saúde fonoaudiológica.

Considerando-se que um dos indicadores da qualidade na atenção, preconizado pelo Sistema Único de Saúde (SUS), é a avaliação da satisfação dos usuários em relação às ações realizadas pelo próprio SUS e, em consonância com a perspectiva de educação em saúde adotada, assumindo que a avaliação deve ser um processo de monitoramento constante das práticas educativas em saúde ${ }^{(17)}$, torna-se imprescindível conhecer a opinião dos participantes em relação ao cumprimento das metas, conteúdo, material, dinâmica, estratégias e relação interpessoal durante o programa. Conforme estudo ${ }^{(17)}$, o resultado obtido sobre a eficiência do programa foi a base para a discussão entre os proponentes e os gestores do serviço com relação ao redimensionamento e/ou à melhoria das ações e estratégias adotadas para atender as necessidades específicas do usuário do serviço. A validade ou não dos dados obtidos com uma avaliação dependerá do uso que se pretenda dar aos resultados ${ }^{(17)}$.

Sendo assim, o objetivo deste estudo foi verificar a satisfação de participantes de um programa educativo em saúde, desenvolvido por meio de rodas de conversa em sala de espera.

\section{MÉTODOS}

O presente estudo foi aprovado pelo Comitê de Ética em Pesquisa do Hospital das Clínicas da Faculdade de Medicina de Ribeirão Preto da Universidade de São Paulo (CEPHCFMRPUSP), processo $n^{\circ} 8802 / 2010$.

Participaram da pesquisa 34 pessoas, sendo 21 do gênero feminino e 13 do gênero masculino, usuários e/ou acompanhantes de frequentadores do CIRHER, que encontravam-se na sala de espera no período de abril a junho de 2011 e que aceitaram participar do Programa de Extensão Universitária "Roda de Conversa: estratégia para promoção da saúde fonoaudiológica". A seleção foi realizada por meio de convite verbal, com apresentação dos objetivos do programa e da pesquisa e assinatura do Termo de Consentimento Livre e Esclarecido.

Para a escolha do melhor dia e horário para o desenvolvimento das rodas de conversa, foi realizado o levantamento do perfil dos frequentadores da sala de espera, em diferentes dias e períodos. Durante as visitas, foi solicitado aos sujeitos que informassem a idade, o gênero e, ainda, se eram usuários do serviço ou acompanhantes, especialidade de atendimento, se havia interesse em participar das futuras rodas de conversa e sugestão de tema. Após o levantamento, ficou definido que as atividades seriam realizadas às sextas-feiras, pela manhã. A divulgação da ação deu-se por meio de cartazes fixados na sala de espera e nos setores de atendimento do CIRHER. Uma semana antes do início das atividades, foi feito o convite verbal, com apresentação dos objetivos do programa e da pesquisa a serem desenvolvidos com os usuários e/ou acompanhantes presentes na sala de espera, no horário previamente determinado para as rodas. 
Para o desenvolvimento das rodas de conversa, as cadeiras foram colocadas de forma que todos ficassem frente a frente, com maior aproximação física e visual entre os participantes e a pesquisadora, propiciando um cenário favorável ao estabelecimento do diálogo. Nesse espaço, foi fixado um banner com o título do programa. Antes de iniciar as atividades, a pesquisadora conversou individualmente com as pessoas presentes na sala de espera, informando-as sobre o tema que seria discutido e solicitando aos interessados que se dirigissem até a roda. A opção em participar ou não da roda daquele dia ficava a critério de cada um. Ao final de cada roda, os participantes recebiam o questionário de avaliação de satisfação, onde havia um campo destinado à sugestão de temas para as próximas rodas. Foram realizadas oito rodas de conversa, durante o programa. Os temas, metas, estratégias e materiais utilizados em cada uma das rodas estão representados na Tabela 1 .

O material educativo utilizado durante as rodas de conversa foi elaborado através de consulta à bibliografia e a sites oficiais (Organização Mundial da Saúde, Ministério da Saúde e Conselho Federal de Fonoaudiologia) especializados e relacionados aos assuntos.

Para a avaliação da satisfação dos participantes, foi elaborado um instrumento (questionário diretivo) composto por guia instrucional, identificação e dez questões com temas relacionados ao conteúdo, estratégias e material pedagógico utilizados durante as rodas de conversa. A escala (Likert 0-5) estabelecida foi "Muito Ruim" (MR), "Ruim" (Ru), "Regular" (R), "Bom" (B), "Muito Bom" (MB), apresentada na forma escrita e com apoio em imagens.

Ao final de cada roda de conversa, os participantes eram convidados a responder individualmente ao instrumento de coleta e a assinar o Termo de Consentimento Livre e Esclarecido.

Para a análise, os questionários foram lidos e separados por roda de conversa. Os dados obtidos foram categorizados e tabulados por meio de estatística não paramétrica. Todos os resultados foram organizados em tabelas do Excel ${ }^{\circledR}$ e, posteriormente, foram calculadas as frequências absoluta $\mathrm{e}$ relativa das respostas obtidas. A seguir, procedeu-se à análise e interpretação dos dados estatísticos, a partir das seguintes categorias: Conteúdo, Material e Importância.

Ressalta-se que o programa foi parte de um Projeto de Cultura Extensão elaborado por um docente-orientador e realizado por um graduando do $4^{\circ}$ ano do curso de Fonoaudiologia, sob supervisão, e que houve um período prévio de dois meses para que o aluno fosse preparado teoricamente e tecnicamente para a ação.

\section{RESULTADOS}

Participaram voluntariamente da pesquisa 34 adultos, sendo 21 do gênero feminino e 13 do gênero masculino, que encontravam-se na sala de espera do CIRHER no período de abril a junho de 2011. Durante o programa de extensão, foram realizadas oito rodas de conversa na sala de espera. Por se tratar de programa de roda de conversa (grupo aberto) com participação voluntária, identificou-se uma variação em relação

Tabela 1. Temática desenvolvida durante as rodas de conversa

\begin{tabular}{|c|c|c|c|c|}
\hline Roda & Tema & Meta & Estratégia & Material \\
\hline 1 & Fonoaudiologia/apresentação & $\begin{array}{l}\text { a) Estabelecer relação de } \\
\text { confiança e interação dialógica } \\
\text { entre os usuários e o mediador } \\
\text { b) Apresentar a Fonoaudiologia }\end{array}$ & $\begin{array}{l}\text { Bate papo entre mediador e } \\
\text { participantes }\end{array}$ & Folder/filmadora \\
\hline 2 & Saúde & $\begin{array}{l}\text { a) Refletir sobre Saúde Geral e } \\
\text { Qualidade de Vida }\end{array}$ & Atividade dialógica mediada & Cartaz/folheto/filmadora \\
\hline 3 & Voz & $\begin{array}{l}\text { a) Refletir sobre cuidados e } \\
\text { prevenção de alterações vocais }\end{array}$ & Atividade dialógica mediada & $\begin{array}{l}\text { Folder campanha da voz 2011/ } \\
\text { filmadora }\end{array}$ \\
\hline 4 & Saúde do idoso & $\begin{array}{l}\text { a) Refletir sobre a Saúde do } \\
\text { Idoso e alterações relacionadas } \\
\text { a Fonoaudiologia }\end{array}$ & Atividade dialógica mediada & Folders/filmadora \\
\hline 5 & Cigarro & $\begin{array}{l}\text { a) Refletir sobre relação entre } \\
\text { o hábito de fumar e alterações } \\
\text { fonoaudiológicas }\end{array}$ & Atividade dialógica mediada & Folheto/filmadora \\
\hline 6 & $\begin{array}{l}\text { Comunicação relação falante } \\
\text { X ouvinte }\end{array}$ & $\begin{array}{l}\text { a) Refletir sobre a relação } \\
\text { falante-ouvinte }\end{array}$ & $\begin{array}{l}\text { Atividade dialógica mediada } \\
\text { "Dinâmica do barbante" }\end{array}$ & Folheto/filmadora \\
\hline 7 & Comunicação & $\begin{array}{l}\text { a) Refletir sobre formas de } \\
\text { comunicação e possíveis } \\
\text { alterações }\end{array}$ & Atividade dialógica mediada & Folheto/filmadora \\
\hline 8 & Gagueira/encerramento & $\begin{array}{l}\text { a) Refletir sobre a Gagueira e } \\
\text { suas manifestações } \\
\text { Encerramento do programa }\end{array}$ & Atividade dialógica mediada & Filmadora \\
\hline
\end{tabular}


ao número de pessoas que integraram as rodas, com mais ou menos cinco usuários com média de idade de 43 anos.

Os participantes da roda quatro $(n=6)$ não aceitaram participar da pesquisa e não responderam ao questionário. Portanto, são apresentados na Tabela 2 os resultados obtidos com a avaliação de sete rodas.

Constatou-se que os participantes avaliaram a temática como satisfatória, com 24,75\% das respostas para B e 73,8\% para MB. A estratégia e a organização foram consideradas
MB (73,2\% e 70,3\%, respectivamente). Os resultados sobre a satisfação em relação ao conteúdo, estratégia e organização estão dispostos na Tabela 3.

A linguagem oral (vocabulário) utilizada pelo responsável foi avaliada como satisfatória (MB) por 75,7\% dos participantes e o material (vídeo, folder, folheto, cartaz e painel) foi considerado MB para 57,2\%. Foram selecionados folders e vídeos disponíveis em meio digital e impresso e confeccionados folhetos, cartazes e painel baseados em documentos institucionais,

Tabela 2. Caracterização dos participantes por roda de conversa

\begin{tabular}{|c|c|c|c|c|c|c|c|c|c|}
\hline \multirow[b]{2}{*}{ Rodas } & \multicolumn{8}{|c|}{$\begin{array}{l}\text { Frequência absoluta } \\
\text { (n) }\end{array}$} & \multirow[b]{2}{*}{ Total } \\
\hline & 1 & 2 & 3 & 4 & 5 & 6 & 7 & 8 & \\
\hline Participantes & 10 & 4 & 4 & 6 & 7 & 5 & 2 & 2 & 40 \\
\hline \multicolumn{10}{|l|}{ Gênero } \\
\hline Feminino & 4 & 3 & 3 & SR & 4 & 3 & 2 & 2 & 21 \\
\hline Masculino & 6 & 1 & 1 & & 3 & 2 & 0 & 0 & 13 \\
\hline \multicolumn{10}{|l|}{ Idade } \\
\hline Mínima & 28 & 28 & 60,5 & SR & 63,3 & 47,7 & 46 & 46 & \\
\hline Média & 53,4 & 45,5 & 52 & SR & 50 & 29 & 36 & 36 & \\
\hline Máxima & 65 & 63 & 69 & SR & 74 & 65 & 56 & 56 & \\
\hline
\end{tabular}

Legenda: $\mathrm{SR}=$ sem resposta

Tabela 3. Satisfação dos participantes em relação ao Conteúdo, Estratégia e Organização

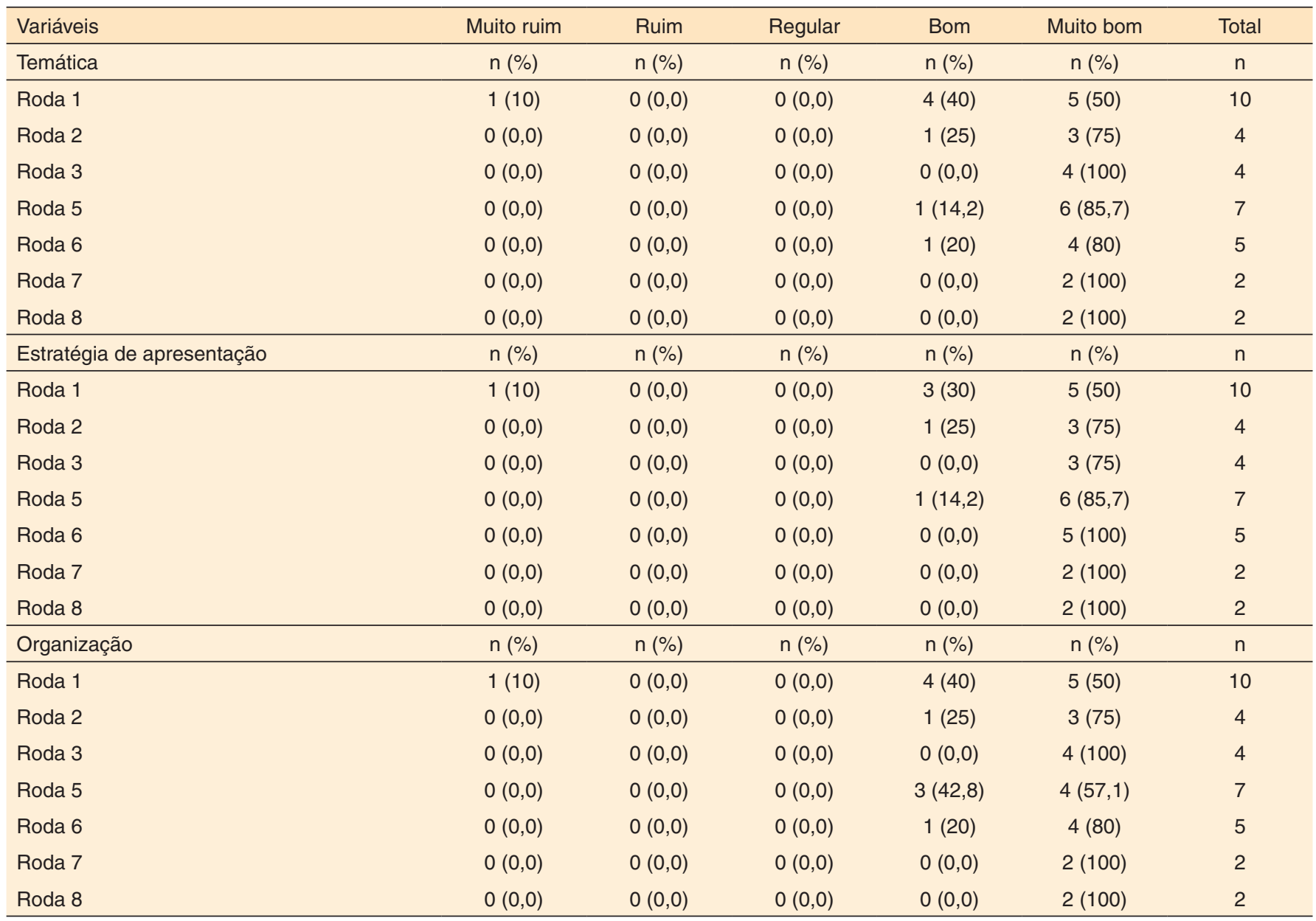


Tabela 4. Satisfação dos participantes em relação à Linguagem e Material

\begin{tabular}{|c|c|c|c|c|c|c|}
\hline Variáveis & Muito ruim & Ruim & Regular & Bom & Muito bom & Total \\
\hline Linguagem & $\mathrm{n}(\%)$ & n (\%) & $\mathrm{n}(\%)$ & $\mathrm{n}(\%)$ & $\mathrm{n}(\%)$ & $\mathrm{n}$ \\
\hline Roda 1 & $1(10)$ & $0(0,0)$ & $1(10)$ & $1(10)$ & $7(70)$ & 10 \\
\hline Roda 2 & $0(0,0)$ & $0(0,0)$ & $0(0,0)$ & $5(50)$ & $5(50)$ & 4 \\
\hline Roda 3 & $0(0,0)$ & $0(0,0)$ & $0(0,0)$ & $0(0,0)$ & $4(100)$ & 4 \\
\hline Roda 5 & $0(0,0)$ & $0(0,0)$ & $0(0,0)$ & $1(14,2)$ & $6(85,7)$ & 7 \\
\hline Roda 6 & $0(0,0)$ & $0(0,0)$ & $0(0,0)$ & $0(0,0)$ & $5(100)$ & 5 \\
\hline Roda 7 & $0(0,0)$ & $0(0,0)$ & $0(0,0)$ & $0(0,0)$ & $2(100)$ & 2 \\
\hline Roda 8 & $0(0,0)$ & $0(0,0)$ & $0(0,0)$ & $0(0,0)$ & $2(100)$ & 2 \\
\hline Material de apoio & $\mathrm{n}(\%)$ & $\mathrm{n}(\%)$ & $\mathrm{n}(\%)$ & $\mathrm{n}(\%)$ & $\mathrm{n}(\%)$ & $\mathrm{n}$ \\
\hline Roda 1 & $0(0,0)$ & $0(0,0)$ & $0(0,0)$ & $5(50)$ & $4(40)$ & 10 \\
\hline Roda 2 & $0(0,0)$ & $0(0,0)$ & $0(0,0)$ & $1(25)$ & $3(75)$ & 4 \\
\hline Roda 3 & $0(0,0)$ & $0(0,0)$ & $0(0,0)$ & $0(0,0)$ & $4(100)$ & 4 \\
\hline Roda 5 & $0(0,0)$ & $0(0,0)$ & $0(0,0)$ & $2(28,5)$ & $3(42,8)$ & 7 \\
\hline Roda 6 & $0(0,0)$ & $0(0,0)$ & $0(0,0)$ & $0(0,0)$ & $5(100)$ & 5 \\
\hline Roda 7 & $0(0,0)$ & $0(0,0)$ & $0(0,0)$ & $0(0,0)$ & $2(100)$ & 2 \\
\hline Roda 8 & $0(0,0)$ & $0(0,0)$ & $0(0,0)$ & $0(0,0)$ & $2(100)$ & 2 \\
\hline
\end{tabular}

Tabela 5. Satisfação dos participantes em relação à importância da roda e transmissão de conhecimento

\begin{tabular}{|c|c|c|c|c|c|c|}
\hline Variáveis & Muito ruim & Ruim & Regular & Bom & Muito bom & Total \\
\hline Importância da roda & $\mathrm{n}(\%)$ & $\mathrm{n}(\%)$ & $\mathrm{n}(\%)$ & $\mathrm{n}(\%)$ & $\mathrm{n}(\%)$ & $\mathrm{n}$ \\
\hline Roda 1 & $0(0,0)$ & $0(0,0)$ & $0(0,0)$ & $2(20)$ & $5(50)$ & 10 \\
\hline Roda 2 & $0(0,0)$ & $0(0,0)$ & $0(0,0)$ & $1(25)$ & $3(75)$ & 4 \\
\hline Roda 3 & $0(0,0)$ & $0(0,0)$ & $0(0,0)$ & $0(0,0)$ & $3(75)$ & 4 \\
\hline Roda 5 & $0(0,0)$ & $0(0,0)$ & $0(0,0)$ & $1(14,2)$ & $4(57,1)$ & 7 \\
\hline Roda 6 & $0(0,0)$ & $0(0,0)$ & $0(0,0)$ & $0(0,0)$ & $5(100)$ & 5 \\
\hline Roda 7 & $0(0,0)$ & $0(0,0)$ & $0(0,0)$ & $0(0,0)$ & $2(100)$ & 2 \\
\hline Roda 8 & $0(0,0)$ & $0(0,0)$ & $0(0,0)$ & $0(0,0)$ & $2(100)$ & 2 \\
\hline Transmissão conhecimento & n (\%) & n (\%) & n (\%) & n (\%) & n (\%) & $n$ \\
\hline Roda 1 & $0(0,0)$ & $0(0,0)$ & $3(30)$ & $3(30)$ & $1(10)$ & 10 \\
\hline Roda 2 & $0(0,0)$ & $0(0,0)$ & $0(0,0)$ & $1(25)$ & $3(75)$ & 4 \\
\hline Roda 3 & $0(0,0)$ & $0(0,0)$ & $1(25)$ & $0(0,0)$ & $2(50)$ & 4 \\
\hline Roda 5 & $0(0,0)$ & $0(0,0)$ & $0(0,0)$ & $0(0,0)$ & $4(57,1)$ & 7 \\
\hline Roda 6 & $0(0,0)$ & $0(0,0)$ & $0(0,0)$ & $2(40)$ & $3(60)$ & 5 \\
\hline Roda 7 & $0(0,0)$ & $0(0,0)$ & $0(0,0)$ & $1(50)$ & $1(50)$ & 2 \\
\hline Roda 8 & $0(0,0)$ & $0(0,0)$ & $0(0,0)$ & $1(50)$ & $1(50)$ & 2 \\
\hline
\end{tabular}

de acordo com os temas previamente propostos pelos usuários da sala de espera (Tabela 4).

Para a questão "O quanto você acha que a roda de conversa foi importante”, obteve-se $69,3 \%$ para MB e para a questão "Você se sente capaz de transmitir os conhecimentos aqui adquiridos”, 44\% de respostas para MB (Tabela 5).

\section{DISCUSSÃO}

O objetivo geral do programa de extensão foi sensibilizar os usuários participantes quanto à saúde fonoaudiológica e geral.
A estratégia utilizada no desenvolvimento do programa vem ao encontro do modelo dialógico de educação em saúde, cujo objetivo é trabalhar com grupos, na expectativa de promover o desenvolvimento da consciência crítica, por intermédio da troca de ideias ${ }^{(6)}$. A opção por realizar as rodas de conversa foi pautada na premissa de que os profissionais da saúde e usuários dos serviços precisam estabelecer uma relação dialógica com base na escuta, no respeito e na valorização das experiências, das histórias de vida e da visão de mundo de cada um ${ }^{(10,17)}$ e de que a educação em saúde é um processo capaz de desenvolver a reflexão e a consciência critica das pessoas sobre as causas 
de seus problemas de saúde, por meio do diálogo ${ }^{(8)}$.

As rodas de conversa tiveram tempo de duração de 20 a 40 minutos, variando em relação à quantidade de participantes em cada uma delas, aproximadamente cinco por roda, com média de idade entre 29 e 53 anos (Tabela 2). Essa variação poderia ser justificada pelo fato de que o número de pessoas na sala de espera era diferente a cada dia e porque as pessoas presentes poderiam ter se recusado a integrar o grupo. Salienta-se que atividades desenvolvidas em sala de espera devem ser flexíveis e o profissional (facilitador) precisa estar preparado para lidar com a diversidade de indivíduos que compõem o grupo e para obter a adesão dos que estão presentes no local, legitimando assim os princípios de autonomia, autogestão e corresponsabilidade pela saúde ${ }^{(4,6,11,12,15)}$.

Pode-se indicar os seguintes aspectos como hipóteses ou fatores intervenientes para a recusa em participar das rodas de conversa: falta de interesse em relação ao tema, utilização do tempo de espera para realizar outras atividades (leitura, assistir televisão, conversar com outros usuários e realização de trabalhos manuais), falta de esclarecimento sobre como seria a participação no programa falta de interesse pessoal em aproveitar a oportunidade para adquirir conhecimento, ou até mesmo o local de realização das rodas que, neste caso, foi a sala de espera, espaço amplo, movimentado e ruidoso. Outra justificativa seria a ocorrência esporádica desse tipo de ação no serviço de saúde e a ausência de estratégias para esse fim, uma vez que se trabalha com a livre demanda, limitando, talvez, a abrangência das ações educativas ${ }^{(2)}$. Não é possível concluir sobre o que de fato contribui para a adesão ou não ao convite, em participar. Sugere-se que, em programas semelhantes, os usuários presentes na sala de espera e que se recusarem a participar, sejam questionados sobre o motivo. Essa informação seria fundamental para a reestruturação do programa, no sentido de incluir estratégias para estimular a adesão do público alvo.

Todo programa educativo em saúde deveria ser avaliado pelos participantes, para que os idealizadores das propostas possam analisar a efetividade da estratégia adotada. Os resultados obtidos com esta pesquisa (Tabela 3 ) indicaram que a temática trabalhada foi satisfatória. Salienta-se que, como prevê o método bidirecional e democrático, os conteúdo foram definidos com a participação efetiva dos usuários da sala de espera e, ao final de cada roda, os participantes poderiam sugerir novos temas ${ }^{(5,6,10,11,15)}$ Considera-se que o modelo adotado foi satisfatório para alcançar a meta de construir e transmitir conhecimento em saúde de forma participativa, levando-se em conta a experiência e o conhecimento prévio de cada participante, bem como sua autonomia ${ }^{(5,6,8,12)}$

Os materiais educativos (tanto os elaborados como os institucionais) foram utilizados como suporte para conduzir a discussão e constatou-se que os participantes mostraram-se satisfeitos com esses materiais. Houve a preocupação com a seleção e elaboração de materiais que abordassem os assuntos de forma simples, clara, contextualizada e adequada ao nível socioeconômico e cultural ${ }^{(4,6,8)}$. A linguagem utilizada pelo facilitador também foi alvo da avaliação e observou-se (Tabela 4), novamente, a satisfação dos participantes. A literatura afirma que só o preparo do profissional responsável para conduzir o diálogo em grupo é que permitiria o acesso às informações trabalhadas ${ }^{(6)}$. Sendo assim, o aluno responsável pela realização do projeto foi previamente preparado $^{(15),}$ para que pudesse estabelecer uma relação simétrica e democrática com o grupo e, ao mesmo tempo, possibilitar a troca, a reflexão e a discussão de forma interativa e dialógica, privilegiando a experiência individual $^{(10-12)}$. O uso de termos técnicos e científicos foi minimizado, na tentativa de aproximar a linguagem acadêmica da comunidade, mas com respaldo teórico ${ }^{(4)}$. Os cuidados citados acima foram tomados para que houvesse a possibilidade de rompimento das barreiras de comunicação e, assim, criar um espaço mais democrático para a construção de conhecimento $^{(11,13)}$. Em programas desse tipo, sempre caberá ao profissional o papel de humanizar as relações, o que requer compromisso social, além de competência técnica e científica em sua área.

Conforme resultados descritos na Tabela 3 , a estratégia e a organização do programa foram avaliadas como satisfatórias pela maioria dos participantes, sugerindo que a roda de conversa foi um recurso capaz de produzir a discussão sobre os assuntos colocados em pauta e de sensibilizar os participantes frente a sua saúde, mostrando-se como cenário promissor e efetivo para a mudança nos ambientes de saúde ${ }^{(10)}$. Supõe-se que o responsável foi flexível para lidar com o dinamismo imposto pela situação, pois em relações democráticas, simétricas e de participação voluntárias, as variáveis são muitas ${ }^{(11,13)}$. É certo que estratégias como essa deveriam estar inseridas como parte do plano de educação em saúde institucional e incorporadas à rotina do serviço em questão, de forma contínua ${ }^{(11,13)}$.

Durante as rodas de conversa, os participantes tiveram a oportunidade de opinar, dividir experiências de vida e compartilhar ideias. Foram momentos muito produtivos, que os motivaram a ser construtores de seus próprios saberes e responsáveis por reconhecê-los como importantes, dando ao grupo a oportunidade de aprofundamento em assuntos de interesse para a área de saúde e Fonoaudiologia. Porém, há que se pensar em estratégias que estimulem as pessoas a participarem desse tipo de ação, não como obrigatoriedade, mas por escolha, e que incentivem a população à autogestão e responsabilidade com sua saúde.

É preciso ofertar aos usuários um espaço para manifestar sua opinião sobre o serviço a ele oferecido. Portanto, considera-se que, apesar de algumas limitações, o instrumento elaborado foi pertinente e possibilitou ao proponente refletir sobre as dificuldades relacionadas ao método e a operacionalização da prática educativa. Na continuidade da avaliação do programa, sugere-se a seleção de um instrumento com método qualitativo, pois, assim, o espaço oferecido para o usuário manifestar sua percepção poderia ser ampliado. Há que se inserir, também, 
um instrumento de autoavaliação, pois a responsabilidade pelo sucesso do programa foi atribuída somente aos participantes. Porém, considera-se um desafio avaliar todos os fatores envolvidos na prática educativa, pois dela participam diversos atores e as situações são dinâmicas e, muitas vezes, imprevisíveis, mesmo para o método científico.

\section{CONCLUSÃO}

Os participantes mostraram-se satisfeitos com o conteúdo, (temática, estratégia de apresentação e organização), com o material (linguagem e material de apoio) e com a importância e transmissão dos conhecimentos partilhados durante o programa socioeducativo em saúde.

\section{REFERÊNCIAS}

1. Berbel DB, Rigolin CCD. Educação e promoção da saúde no Brasil através de

Campanhas públicas. Revista Brasileira de Ciência, Tecnologia e Sociedade. 2011;1(2):25-38.

2. Lima RT, Barros JC, Melo MRA, Sousa MG. Educação em saúde e nutrição em João Pessoa, Paraíba. Rev Nutr. 2000;13(1):29-36.

3. Gilvan FF. Educação em saúde em grupo: olhar da enfermeira e do usuário hipertenso [dissertação]. Fortaleza: Universidade Estadual do Ceará; 2011. 174p.

4. Bizzo MLG. Difusão científica, comunicação e saúde. Cad Saúde Pública. 2002;18(1):307-14.

5. Matos MR, Meneguetti 1C, Gomes ALZ. Uma experiência em comunicação e saúde. Interface. 2009;13(31):437-47.

6. Brites LS, Souza, APR, Lessa, AH. Fonoaudiólogo e agente comunitário de saúde: uma experiência educativa. Rev Soc Bras Fonoaudiol. 2008;13(3):258-66.

7. Silva CMC, Meneghim MC, Pereira AC, Mialhe FL. Educação em saúde: uma reflexão histórica de suas práticas. Ciênc Saúde Coletiva. 2010;15(5):2539-50.
8. Alves GG, Aerts D. As práticas educativas em saúde e a Estratégia Saúde da Família. Ciênc Saúde Coletiva. 2011;16(1):319-25.

9. Figueiredo MFS, Rodrigues-Neto JF, Leite MTS. Modelos aplicados às atividades de educação em saúde. Rev Bras Enferm. 2010;63(1):117-21.

10. Ribeiro PJ, Aguiar LAK, Toledo CF, Barros SMO, Borges DR. Programa educativo em esquistossomose: modelo de abordagem metodológica. Rev Saúde Pública. 2004;38(3):415-21.

11. Gomes AMA, Sampaio JJC, Carvalho MGB, Nations MK, Alves MSCF. Código dos direitos e deveres da pessoa hospitalizada no SUS: o cotidiano hospitalar na roda de conversa. Interface. 2008;12(27):773-82.

12. Deslandes SF, Mitre RMA. Processo comunicativo e humanização em saúde. Interface. 2009;13(supl.1):641-9.

13. Jeolás LS, Ferrari RAP. Oficinas de prevenção em um serviço de saúde para adolescentes: espaço de reflexão e de conhecimento compartilhado. Ciênc Saúde Coletiva. 2003;8(2):611-20.

14. Mendonça JA, Lemos SMA. Promoção da saúde e ações fonoaudiológicas em educação infantil. Rev CEFAC. 2011;13(6):1017-30.

15. Custódio IL. Ações de educação em saúde no controle do tabagismo nos ambientes de trabalho. In: $61^{\circ}$ Congresso Brasileiro de Enfermagem; 2009. dez 07-10. Fortaleza. Congresso Brasileiro de Enfermagem; Fortaleza: 2009.

16. Braga TMS, Oliveira JP. Salas de espera espaços com potencial para ações que integrem a educação e a saúde. In: Marcolino J, Zaboroski AP, Oliveira JPO. Perspectivas atuais em fonoaudiologia: refletindo sobre ações na comunidade. São José do Campos: Pulso, 2010. cap. 8.

17. Rojas MF, Simoni AL, Morais BBO, Rasteiro R. Avaliação do impacto do Programa de Promoção da Saúde pelos usuários. In: Amorim DS, Alessi NP, Gáttas MLB. Práticas interdisciplinares na área da saúde. Ribeirão Preto: Holos, 2007. p.114-28. 